\title{
Childhood adversities and laboratory pain perception
}

\author{
This article was published in the following Dove Press journal: \\ Neuropsychiatric Disease and Treatment \\ 19 August 2015 \\ Number of times this article has been viewed
}

\author{
Karoline Pieritz \\ Winfried Rief \\ Frank Euteneuer \\ Division of Clinical Psychology and \\ Psychotherapy, Philipps University \\ Marburg, Marburg, Germany
}

\begin{abstract}
Childhood adversity has frequently been related to a wide range of psychosomatic complaints in adulthood. The present study examined the relationship between different forms of childhood adversity and laboratory measures of pain. Heat pain tolerance and perceived heat pain intensity were measured in a community-based sample of 62 women (aged 20-64 years). Participants completed the Childhood Trauma Questionnaire (CTQ), which assesses five forms of childhood adversity: physical abuse, sexual abuse, emotional abuse, physical neglect, and emotional neglect. Somatic symptoms, depressive symptoms, and pain catastrophizing were assessed as potential mediators. Bivariate analyses indicated that emotional abuse but no other forms of childhood adversity were significantly related to decreased heat pain tolerance ( $r=-0.27 ; P<0.05$ ). Accordingly, multiple regression analyses revealed that only emotional abuse was a significant predictor of heat pain tolerance $(\beta=-0.62 ; P=0.034)$ when entering all CTQ subscales simultaneously. Although emotional abuse was also related to somatic symptoms, depressive symptoms, and pain catastrophizing, none of these variables mediated the relationship between childhood adversity and laboratory pain $(P>0.1)$. No significant associations were found between any forms of childhood adversity and heat pain intensity. Our findings indicate that the severity of emotional childhood abuse is associated with decreased pain tolerance, an affective component of pain, but not with heat pain intensity, which has been described as a sensory component of pain.
\end{abstract}

Keywords: childhood adversity, emotional abuse, pain tolerance, pain intensity, somatic symptoms

\section{Introduction}

Adverse childhood experiences have been linked to the development of various physical and mental health problems in adulthood. Such negative health outcomes include conditions accompanied by distressing somatic symptoms such as somatization disorder, chronic pain, conversion disorder, functional somatic syndromes, and hypochondriasis. ${ }^{1-6}$ One possible explanation for the association between adverse childhood experiences and somatic complaints might be that early life stressors affect biological pathways which amplify the perception of bodily signals. ${ }^{3}$ For example, adverse childhood experiences have been related to a dysregulation of the hypothalamic-pituitary-adrenal axis ${ }^{7,8}$ and inflammatory immune alterations, ${ }^{9,10}$ features which have also been associated with somatic complaints and increased pain perception, respectively. ${ }^{11}$

If adverse childhood experiences lead to an amplification of the perception of bodily signals, subjects with more adverse childhood experiences should be characterized by an increased sensitivity to laboratory-induced pain. However, little research has been done on this issue, and findings have been mixed. One study examined pain perception 
in female patients with painful gastrointestinal disorders with and without a history of sexual/physical abuse. Compared to non-abused patients, abused patients had significantly lower pressure pain thresholds and lower cognitive standards for judging stimuli as noxious. ${ }^{12}$ In another study, including women with irritable bowel syndrome and healthy controls with and without a history of sexual abuse, no abuse-related differences emerged for the perception of pain induced by rectal distension. ${ }^{13}$ Finally, a study examining healthy young women and men found no differences for thermal or ischemic pain tolerance between participants with and without a self-reported history of sexual or physical abuse. However, women with a positive history of abuse showed significantly decreased sensitivity to experimentally induced pain compared to women with no childhood abuse history. There were no abuse-related group differences for men. ${ }^{14}$

So far, the most commonly studied forms of childhood adversity have been sexual and physical abuse. However, assessing other types of adversity may be important to fully understand the relationship between adverse childhood experiences and pain perception in adulthood. The present study aims to extend the existing findings on childhood adversities and pain by examining the association between five different forms of childhood adversity and two components of pain: an affective component of pain (ie, heat pain tolerance) and a sensory component of pain (ie, heat pain intensity). Since childhood adversity has been linked with depressive mood, somatic symptoms, and pain catastrophizing, ${ }^{1-5,15,16}$ and these variables in turn have been linked to altered pain perception, ${ }^{17-20}$ we further examined whether they mediate the association between childhood adversity, pain tolerance and pain intensity. We firstly hypothesized that more exposure to childhood adversity would be associated with experiencing more pain (ie, decreased tolerance and increased sensitivity to laboratory heat pain). We further hypothesized that these associations would be mediated by the severity of depressive symptoms, somatic symptoms, and/or pain catastrophizing.

\section{Methods}

\section{Participants}

Sample characteristics are shown in Table 1. Participants were a nonclinical sample of 62 women (aged 20-64 years) recruited from the general population via advertisements, leaflets, and press releases in local newspapers. There were no specific inclusion criteria except female sex and age between 18 and 65 years. We only included women since a number of recommendations suggest investigating female samples because of the greater prevalence of pain conditions in women
Table I Sample characteristics $(\mathrm{N}=62)$

\begin{tabular}{|c|c|}
\hline Variable & Mean (SD) \\
\hline Age (years) & $34.4(12.2)$ \\
\hline Body mass index $\left(\mathrm{kg} / \mathrm{m}^{2}\right)$ & $23.2(4.9)$ \\
\hline \multicolumn{2}{|l|}{ Menstrual cycle phase, $\mathrm{n}(\%)$} \\
\hline Menstruation phase & $12(19.4)$ \\
\hline Follicular phase & $\mathrm{I}(\mathrm{I} .6)$ \\
\hline Ovulation phase & $10(16.1)$ \\
\hline Luteal phase & $12(19.4)$ \\
\hline Premenstrual phase & $12(19.4)$ \\
\hline Menopause & $13(21.0)$ \\
\hline Depressive symptoms (PHQ-9, 0-27) & $5.3(4.0)$ \\
\hline Somatic symptoms (PHQ-I5, 0-30) & $6.3(4.0)$ \\
\hline Pain catastrophizing (PCS, 0-52) & $25.7(9.3)$ \\
\hline CTQ total score $(25-125)$ & $40.2(16.4)$ \\
\hline Emotional abuse (5-25) & $9.7(5.0)$ \\
\hline Physical abuse (5-25) & $6.4(3.4)$ \\
\hline Sexual abuse $(5-25)$ & $6.5(4.2)$ \\
\hline Emotional neglect (5-25) & II $.0(4.9)$ \\
\hline Physical neglect (5-25) & $6.7(2.4)$ \\
\hline Heat pain tolerance $\left({ }^{\circ} \mathrm{C}\right)$ & $46.4(2.3)$ \\
\hline Heat pain intensity (VAS) & $6.2(2.0)$ \\
\hline $\begin{array}{l}\text { Notes: All values are shown as mean (SD), e) } \\
\text { is } n(\%) \text {. Values in parentheses indicate the ra } \\
\text { Abbreviations: CTQ, Childhood Trauma Q } \\
\text { Scale; PHQ-9, nine-item depression subscale } \\
\text { PHQ-15, I5-item somatic symptom subscale } \\
\text { SD, standard deviation; VAS, visual analog sca }\end{array}$ & $\begin{array}{l}\text { le phase, which } \\
\text { Catastrophizing } \\
\text { Questionnaire; } \\
\text { Questionnaire; }\end{array}$ \\
\hline
\end{tabular}

and because of differences in pain processing between men and women. Furthermore, interaction effects of experimenter sex and participant sex should be avoided. ${ }^{21-23}$ The study was conducted between April and June 2012. It was approved by the ethics committee of the Philipps University of Marburg (Marburg, Germany). Before participation and giving of informed consent, telephone screenings were conducted using a standardized checklist to control for the following exclusion criteria: neurological disease (eg, epilepsy, multiple sclerosis, dementia, neuropathy), metabolic disorders (eg, diabetes), any organic illnesses with a significant impact on pain perception (eg, Raynaud's phenomenon, irritable bowel syndrome, interstitial cystitis, fibromyalgia), cardiovascular disease, psychotic symptoms, and alcohol and/or drug abuse.

\section{Childhood adversity}

Exposure to childhood adversity was assessed using the German version of the Childhood Trauma Questionnaire (CTQ)-Short Form. ${ }^{24}$ This self-report questionnaire measures five forms of childhood adversity including emotional, physical, and sexual abuse as well as emotional and physical neglect. Each subscale consists of five items, rated on a five-point Likert scale from 1 (never true) to 5 (very often true). The CTQ subscale scores range from 5 to 25 and the total score ranges 
from 25 to 125. Similar to the American original, ${ }^{25}$ the German CTQ version has been proved to be a reliable and valid tool for the retrospective assessment of child maltreatment. ${ }^{26,27}$

\section{Depressive symptoms}

Depressive symptoms were assessed using the German version of the nine-item depression subscale of the Patient Health Questionnaire (PHQ-9). ${ }^{28}$ This self-administered depression module scores each of the nine Diagnostic and Statistical Manual of Mental Disorders, Fifth Edition (DSM-5) criteria ${ }^{29}$ of depression from 0 (not at all) to 3 (nearly every day). The total score for the nine items ranges from 0 to $27(0-4=$ minimal; 5-14= mild; $15-19=$ moderate; $20-27=$ severe depression). The German version of the PHQ-9 is considered to be a reliable and valid measure of depressive symptom severity. ${ }^{28}$

\section{Somatic symptoms}

Participants completed the somatic symptom subscale of the Patient Health Questionnaire (PHQ-15), a 15-item self-report questionnaire covering the most prevalent symptoms of DSM-5 somatic symptom disorder. Subjects are asked to rate the severity of 13 different symptoms from 0 (not bothered at all) to 2 (bothered a lot). Two additional physical symptoms (feeling tired or having little energy, trouble sleeping) are contained in the PHQ-9. Thus, the total score ranges from 0 to $30(0-4=$ minimal; $5-9=$ low $; 10-14=$ medium; $15-30=$ high somatic symptom severity). The PHQ-15 is considered a reliable and valid instrument for measuring somatic symptom severity ${ }^{30,31}$ and was strongly associated with functional impairment, disability, and health care use. ${ }^{32}$

\section{Pain catastrophizing}

Participants completed the German version of the Pain Catastrophizing Scale (PCS) ${ }^{33}$ in order to assess the extent of catastrophizing thoughts, feelings, and behaviors when they are in pain. The PCS is a 13-item self-report questionnaire with a five-point Likert-style response scale ranging from 0 (strongly disagree) to 4 (strongly agree). Total scores range from 0 to $52(30=75$ th percentile, clinically relevant level of catastrophizing). The psychometric properties of the German version of the PCS were comparable to those reported in previous studies for the original English version. ${ }^{34}$

\section{Laboratory pain measures}

Individuals' heat pain tolerance was determined using thermal stimuli between $32^{\circ} \mathrm{C}$ and $52^{\circ} \mathrm{C}$. Stimuli were delivered to the nondominant forearm via a $3 \times 3 \mathrm{~cm}$ Peltier-based thermode (TSA II: Thermal Sensory Analyzer; Medoc Ltd, Israel).
Heat stimulation started at $32^{\circ} \mathrm{C}$ and rose with a slope of $0.5^{\circ} \mathrm{C}$ per second. Individuals were asked to stop the heat stimulus by pressing a button when they could not stand it any longer. For further analyses, heat pain tolerance was determined by calculating the average of three measurements.

Heat pain intensity was assessed directly after each of the three pain tolerance measurements using a visual analog scale (VAS). The VAS consisted of a $100 \mathrm{~mm}$-long horizontal line representing a continuum of pain intensity. The VAS ranged from "no pain" (0 mm) to "worst imaginable pain" (100 mm). Participants were asked to make a single mark on the line indicating their present pain intensity. The individual scores were determined by measuring the distance $(\mathrm{mm})$ between the "no pain" anchor and the patient's mark. For further analyses, an overall intensity mean value was computed by averaging the three intensity ratings. The VAS is widely used by anesthesia providers when assessing the intensity of acute pain in clinical research. It provides sensitive measurements, since subjects may mark any point on the line between the two verbal anchors. ${ }^{35}$

\section{Confounding variables}

Since higher age ${ }^{36}$ and a higher body mass index (BMI) ${ }^{37}$ may decrease pain tolerance and increase pain sensitivity and because of contradictory findings concerning the influence of menstrual cycle phase on pain perception, ${ }^{38,39}$ these variables were considered as potential confounders in the analyses.

\section{Statistical analyses}

Statistical analyses were carried out using IBM SPSS Statistics version 22.0 for Windows (IBM Corporation, Armonk, NY, USA). Since not all variables were normally distributed, Spearman's rank correlations were conducted to examine bivariate associations between study variables.

To examine the relative impact of different forms of childhood adversity on laboratory heat pain tolerance and heat pain intensity, we performed hierarchical regression analyses with potential confounders (age, BMI, phase in menstrual cycle) entered on step 1 and all five CTQ subscales (emotional abuse, physical abuse, sexual abuse, emotional neglect, physical neglect) simultaneously entered on step 2 .

To test for potential mediation effects of depressive symptoms (PHQ-9), self-reported somatic symptoms (PHQ-15), and pain catastrophizing (PCS) in the relationship between CTQ subscales and laboratory heat pain perception, exploratory simple mediation analyses were run using PROCESS model 4 for SPSS. ${ }^{40}$ Potential confounding variables such as age, BMI, and menstrual cycle phase were included as covariates. 


\section{Results \\ Childhood adversity and heat pain tolerance}

Bivariate analyses revealed a significant association between emotional abuse and heat pain tolerance $(r=-0.27, P<0.05)$ (Table 2). There were no significant associations between heat pain tolerance and any other CTQ subscale $(P>0.1)$ (Table 2$)$. Results indicate that more exposure to adverse emotional childhood experiences is associated with a decreased tolerance to heat pain. When entering all CTQ subscales simultaneously into a multiple regression model (adjusted for age, BMI, and menstrual cycle phase), emotional abuse significantly predicted heat pain tolerance $(\beta=-0.62 ; P=0.034)$ (Table 3 ). Additionally, the emotional neglect subscale tended to predict heat pain tolerance $(\beta=0.45 ; P=0.095)$ (Table 3$)$. The relationship between emotional abuse and heat pain tolerance was not mediated by depressive symptoms, somatic symptoms, and pain catastrophizing $(P>0.1)$ (results not shown).

\section{Childhood adversity and heat pain intensity}

Bivariate analyses revealed no significant associations between laboratory heat pain intensity and any of the CTQ subscale scores $(P>0.1)$ (Table 2). When entering all CTQ subscales simultaneously into a multiple regression model (adjusted for age, BMI, and menstrual cycle phase), sexual abuse and emotional neglect tended to predict laboratory heat pain intensity $(P<0.1)$ (Table 3). This trend indicates that the more exposure to these types of childhood adversity, the higher was the likelihood of rating a stimulus as painful. These relationships were not mediated by depressive symptoms, somatic symptoms, or pain catastrophizing $(P>0.1)$ (results not shown).

\section{Further results}

Bivariate analyses revealed significant associations between depressive symptoms and all five CTQ subscales (Table 2). Self-reported somatic symptoms were significantly associated with adverse emotional childhood experiences (Table 2). Pain catastrophizing was significantly associated with all CTQ subscales except physical neglect (Table 2). In all cases, the strongest associations were found for the emotional abuse subscale. Results indicate that exposure to adverse childhood experiences, especially emotional abuse, leads to more selfreported depressive symptoms, more somatic symptoms, and higher pain catastrophizing in adulthood.

\section{Discussion}

The primary objective of this study was to examine the association of different forms of childhood adversity with pain tolerance and pain intensity. Our main finding is that

Table 2 Spearman correlations between study variables $(\mathrm{N}=62)$

\begin{tabular}{|c|c|c|c|c|c|c|c|c|c|c|c|}
\hline & $\begin{array}{l}\text { Physical } \\
\text { abuse }\end{array}$ & $\begin{array}{l}\text { Sexual } \\
\text { abuse }\end{array}$ & $\begin{array}{l}\text { Emotional } \\
\text { neglect }\end{array}$ & $\begin{array}{l}\text { Physical } \\
\text { neglect }\end{array}$ & $\begin{array}{l}\text { Heat pain } \\
\text { tolerance }\end{array}$ & $\begin{array}{l}\text { Heat pain } \\
\text { intensity }\end{array}$ & PHQ-9 & PHQ-I 5 & PCS & Age & BMI \\
\hline $\begin{array}{l}\text { Emotional } \\
\text { abuse }\end{array}$ & $0.52^{* *}$ & $0.44^{* *}$ & $0.69 * *$ & $0.48^{* *}$ & $-0.27^{*}$ & 0.02 & $0.46 * *$ & $0.35 * *$ & $0.45 * *$ & $0.26 *$ & 0.04 \\
\hline $\begin{array}{l}\text { Physical } \\
\text { abuse }\end{array}$ & & $0.36 * *$ & $0.54 * *$ & $0.57 * *$ & -0.25 & 0.00 & $0.30 *$ & 0.17 & $0.27^{*}$ & 0.10 & 0.24 \\
\hline $\begin{array}{l}\text { Sexual } \\
\text { abuse }\end{array}$ & & & 0.20 & 0.13 & -0.12 & 0.07 & $0.33^{*}$ & 0.23 & $0.35 * *$ & 0.08 & 0.01 \\
\hline $\begin{array}{l}\text { Emotional } \\
\text { neglect }\end{array}$ & & & & $0.57^{* *}$ & -0.05 & 0.09 & $0.27^{*}$ & 0.24 & $0.32 *$ & 0.21 & 0.02 \\
\hline $\begin{array}{l}\text { Physical } \\
\text { neglect }\end{array}$ & & & & & -0.13 & 0.03 & $0.28 *$ & 0.24 & 0.25 & 0.15 & 0.08 \\
\hline $\begin{array}{l}\text { Heat pain } \\
\text { tolerance }\end{array}$ & & & & & & 0.09 & -0.06 & -0.17 & -0.18 & -0.10 & $-0.27^{*}$ \\
\hline $\begin{array}{l}\text { Heat pain } \\
\text { intensity }\end{array}$ & & & & & & & -0.11 & 0.04 & 0.08 & -0.02 & -0.10 \\
\hline PHQ-9 & & & & & & & & $0.66 * *$ & $0.42 * *$ & -0.16 & $-0.27^{*}$ \\
\hline PHQ-I5 & & & & & & & & & $0.43 * *$ & -0.20 & -0.03 \\
\hline PCS & & & & & & & & & & -0.06 & -0.02 \\
\hline $\begin{array}{l}\text { Age } \\
\text { BMI }\end{array}$ & & & & & & & & & & & 0.24 \\
\hline
\end{tabular}

Notes: $* P<0.05 ; * * P<0.01$.

Abbreviations: BMI, body mass index; PCS, Pain Catastrophizing Scale; PHQ-9, nine-item depression subscale of the Patient Health Questionnaire; PHQ-I5, I5-item somatic symptom subscale of the Patient Health Questionnaire. 
Table 3 Predicting laboratory heat pain tolerance and intensity by CTQ subscale scores using hierarchical regression analyses $(\mathrm{N}=62)$

\begin{tabular}{|c|c|c|c|c|c|c|c|c|}
\hline & \multicolumn{4}{|c|}{ Heat pain tolerance } & \multicolumn{4}{|c|}{ Heat pain intensity } \\
\hline & $b$ & SE of $b$ & $\beta$ & $P$-value & $b$ & SE of $b$ & $\beta$ & $P$-value \\
\hline \multicolumn{9}{|l|}{ Step I } \\
\hline Age & -0.04 & 0.03 & -0.22 & $P=0.197$ & -0.01 & 0.03 & -0.07 & $P=0.688$ \\
\hline Body mass index & -0.07 & 0.06 & -0.15 & $P=0.262$ & -0.05 & 0.06 & -0.11 & $P=0.418$ \\
\hline Menstrual cycle phase & -0.11 & 0.22 & -0.09 & $P=0.6 \mathrm{II}$ & 0.12 & 0.19 & 0.11 & $P=0.519$ \\
\hline \multicolumn{9}{|l|}{ Step 2} \\
\hline Age & -0.04 & 0.03 & -0.22 & $P=0.197$ & -0.02 & 0.03 & -0.12 & $P=0.503$ \\
\hline Body mass index & -0.07 & 0.07 & -0.15 & $P=0.279$ & -0.03 & 0.06 & -0.07 & $P=0.648$ \\
\hline Menstrual cycle phase & -0.23 & 0.22 & -0.18 & $P=0.306$ & 0.08 & 0.20 & 0.07 & $P=0.690$ \\
\hline Emotional abuse & -0.28 & 0.13 & -0.62 & $P=0.034$ & -0.14 & 0.11 & -0.36 & $P=0.218$ \\
\hline Physical abuse & -0.05 & 0.17 & -0.08 & $P=0.753$ & -0.10 & 0.15 & -0.16 & $P=0.535$ \\
\hline Sexual abuse & 0.11 & 0.09 & 0.21 & $P=0.203$ & 0.14 & 0.08 & 0.30 & $P=0.075$ \\
\hline Emotional neglect & 0.21 & 0.12 & 0.45 & $P=0.095$ & 0.19 & 0.11 & 0.47 & $P=0.093$ \\
\hline \multirow[t]{2}{*}{ Physical neglect } & -0.04 & 0.25 & -0.05 & $P=0.863$ & -0.04 & 0.218 & -0.05 & $P=0.852$ \\
\hline & \multicolumn{4}{|c|}{$R^{2}=0.06$ for step I; $\Delta R^{2}=0.10$ for step $2, \mathrm{~ns}$} & \multicolumn{4}{|c|}{$R^{2}=0.05$ for step I; $\Delta R^{2}=0.08$ for step $2, \mathrm{~ns}$} \\
\hline
\end{tabular}

Notes: $b=$ unstandardized regression coefficient; $\beta=$ standardized regression coefficient; $P=$ significance value; $R^{2}=$ total variance explained by the model; $\Delta R^{2}=$ variance explained by CTQ subscales after adjusting for age, body mass index, and menstrual cycle phase.

Abbreviations: CTQ, Childhood Trauma Questionnaire; ns, not significant; SE, standard error.

women who experience more emotional abuse exhibited lower levels of pain tolerance, an affective component of pain. This result remained robust after adjusting for possible confounders such as age, BMI, and menstrual cycle phase in multiple regression analyses.

Our finding is consistent with previous research by Scarinci et al reporting lower pressure pain thresholds in abused compared to non-abused women with gastrointestinal disorders. Using sensory decision theory methods, the authors found no group difference with respect to the discrimination ability of stimulus intensity. However, abused patients exhibited lower cognitive standards for judging stimuli as noxious. Scarinci et al therefore concluded that psychosocial factors rather than sensory factors underlie the difference in pain threshold levels. ${ }^{12}$ Nevertheless, there are contradictory findings suggesting no tolerance differences for pain from rectal distension in abused women with irritable bowel syndrome ${ }^{13}$ and no difference for thermal or ischemic pain tolerance in healthy participants with a history of abuse. ${ }^{14}$ However, all studies conducted so far studied sexual or physical abuse only. All of them applied different pain stimuli and investigated different samples, so comparing results is difficult. Since previous studies addressing this issue primarily focused on patients derived from clinical settings, results may also be confounded by the severity of clinical pain. The present study examined a nonclinical community-based sample of women between 18 and 65 years to increase validity.
Research examining the relationship between different forms of childhood adversity and the severity of self-reported somatic/pain complaints in adulthood found the strongest associations for emotional abuse. ${ }^{15,41,42}$ To our knowledge, the present study is the first to demonstrate a similar association for emotional childhood adversity and laboratory pain tolerance.

The connection of emotional childhood adversity and decreased pain tolerance might be explained by a common affective component in both of them. For instance, earlier findings have suggested a particular association between emotional childhood adversity and difficulties concerning the ability to regulate one's emotions, including the acceptance of negative emotions, controlling impulsive behaviors, and limited access to effective emotion-regulation strategies. ${ }^{43-45}$ A further consequence may be an amplified response to stressful life events, including the affective response to pain and other somatic complaints. Potential underlying neurobiological changes such as a dysregulation of the hypothalamicpituitary-adrenal axis, neuroendocrine changes, ${ }^{3,46-48}$ and inflammatory immune alterations ${ }^{9,10}$ have frequently been found in individuals with a history of childhood adversity. Brain imaging research also suggests structural changes (eg, corpus callosum, cerebellum, prefrontal cortex) as well as functional changes (eg, anterior cingulate cortex, amygdala) in brain regions that have been linked to both the processing of emotional pain as well as the affective component of physical pain. ${ }^{47,48}$ 
Self-reported depressive symptoms, somatic symptoms, and pain catastrophizing did not mediate the relationship between childhood adversity and laboratory heat pain tolerance and intensity. However, results for bivariate analyses of CTQ subscales and self-report measures showed a similar association pattern as for laboratory pain outcomes. This finding indicates that exposure to childhood adversity, especially adverse emotional experiences, is not only associated with decreased pain tolerance but with an increased impairment due to perceived somatic symptoms, higher pain catastrophizing, and depressive symptoms as well. Our findings are consistent with those of the previously mentioned studies reporting similar associations between emotional childhood adversity and somatic complaints in adulthood ${ }^{15,41,42}$ and one study suggesting associations between all types of childhood adversity and pain catastrophizing scores, with the strongest associations for emotional abuse. ${ }^{15}$ Clinical studies reporting higher trauma rates in patients with fibromyalgia and other chronic pain syndromes support this relationship.,49 The association between childhood maltreatment in general and depression in later life has been well established. ${ }^{3,50}$ A particular association with emotional abuse has been proposed as well. ${ }^{16,51,52}$

Results of the present study add to the growing evidence supporting a relationship between exposure to childhood adversity and altered pain perception in adulthood. They extend previous research by demonstrating that especially a history of emotional childhood adversity is associated with decreased pain tolerance, an affective component of pain. This finding suggests that an affective component seems to play a major role in the association between childhood adversity and pain/somatic complaints in adulthood. It further emphasizes the importance of assessing multiple types of childhood adversity and their relative impact on different components of pain perception and somatic outcomes as well as examining potential mediating and confounding factors on this relationship. Our findings also may have important clinical implications for the treatment and prevention of pain and related disorders. Practitioners working in the field of pain should consider a patient's history of abuse and consider it in their treatment. Studies have shown that an additional treatment of psychological factors accompanying the experience of pain is superior to an exclusively physical treatment. ${ }^{53-55}$

This study has a number of limitations. First, the sample size was relatively small. Replication of our results in larger samples is necessary. Second, causality for these associations cannot be determined. Prospective studies which focus on the longitudinal relationship between different types of childhood adversity and pain perception and on other potential mediators or moderators may be promising. An additional limitation is that childhood adversity was assessed via questionnaire. Although the questionnaire used in this study has been shown to be reliable and valid, ${ }^{25-27}$ inclusion of additional measures (eg, interview, peer evaluation) may be beneficial.

\section{Conclusion}

Our findings suggest that the severity of emotional childhood adversity is associated with decreased pain tolerance, an affective component of pain, but not with heat pain intensity, which has been described as a sensory component of pain.

\section{Disclosure}

The authors report no conflicts of interest in this work.

\section{References}

1. Chen LP, Murad MH, Paras ML, et al. Sexual abuse and lifetime diagnosis of psychiatric disorders: systematic review and meta-analysis. Mayo Clin Proc. 2010;85(7):618-629.

2. Wegman HL, Stetler C. A meta-analytic review of the effects of childhood abuse on medical outcomes in adulthood. Psychosom Med. 2009; 71(8):805-812.

3. Paras ML, Murad MH, Chen LP, et al. Sexual abuse and lifetime diagnosis of somatic disorders: a systematic review and meta-analysis. JAMA. 2009;302(5):550-561.

4. Arnow BA. Relationships between childhood maltreatment, adult health and psychiatric outcomes, and medical utilization. J Clin Psychiatry. 2004;65 Suppl 1:10-15.

5. Afari N, Ahumada SM, Wright LJ, et al. Psychological trauma and functional somatic syndromes: a systematic review and meta-analysis. Psychosom Med. 2014;76(1):2-11.

6. Mostoufi SM, Strachan E, Chopko L, et al. Adverse childhood experiences, health perception, and the role of shared familial factors in adult twins. Child Abuse Negl. 2013;37(11):910-916.

7. Cicchetti D, Rogosch FA. Diverse patterns of neuroendocrine activity in maltreated children. Dev Psychopathol. 2001;13(3):677-693.

8. Heim C, Newport DJ, Heit S, et al. Pituitary-adrenal and autonomic responses to stress in women after sexual and physical abuse in childhood. JAMA. 2000;284(5):592-597.

9. Carpenter LL, Gawuga CE, Tyrka AR, Lee JK, Anderson GM, Price LH. Association between plasma IL-6 response to acute stress and early-life adversity in healthy adults. Neuropsychopharmacology. 2010;35(13): 2617-2623.

10. Lu S, Peng H, Wang L, et al. Elevated specific peripheral cytokines found in major depressive disorder patients with childhood trauma exposure: a cytokine antibody array analysis. Compr Psychiatry. 2013; 54(7):953-961.

11. Rief W, Hennings A, Riemer S, Euteneuer F. Psychobiological differences between depression and somatization. J Psychosom Res. 2010; 68(5):495-502.

12. Scarinci IC, McDonald-Haile J, Bradley LA, Richter JE. Altered pain perception and psychosocial features among women with gastrointestinal disorders and history of abuse: a preliminary model. Am J Med. 1994; 97(2):108-118.

13. Whitehead WE, Crowell MD, Davidoff AL, Palsson OS, Schuster MM. Pain from rectal distension in women with irritable bowel syndrome: relationship to sexual abuse. Dig Dis Sci. 1997;42(4):796-804. 
14. Fillingim RB, Edwards RR. Is self-reported childhood abuse history associated with pain perception among healthy young women and men? Clin J Pain. 2005;21(5):387-397.

15. Sansone RA, Watts DA, Wiederman MW. Childhood trauma and pain and pain catastrophizing in adulthood: a cross-sectional survey study. Prim Care Companion CNS Disord. 2013;15(4).

16. Gibb BE, Chelminski I, Zimmerman M. Childhood emotional, physical, and sexual abuse, and diagnoses of depressive and anxiety disorders in adult psychiatric outpatients. Depress Anxiety. 2007;24(4):256-263.

17. Sherman JJ, LeResche L, Huggins KH, Mancl LA, Sage JC, Dworkin SF. The relationship of somatization and depression to experimental pain response in women with temporomandibular disorders. Psychosom Med. 2004;66(6):852-860.

18. Euteneuer F, Schwarz MJ, Hennings A, et al. Depression, cytokines and experimental pain: evidence for sex-related association patterns. $J$ Affect Disord. 2011;131(1-3):143-149.

19. Trost Z, Strachan E, Sullivan M, Vervoort T, Avery AR, Afari N. Heritability of pain catastrophizing and associations with experimental pain outcomes: a twin study. Pain. 2015;156(3):514-520.

20. Sachs-Ericsson N, Kendall-Tackett K, Hernandez A. Childhood abuse, chronic pain, and depression in the National Comorbidity Survey. Child Abuse Negl. 2007;31(5):531-547.

21. Greenspan JD, Craft RM, LeResche L, et al; Consensus Working Group of the Sex, Gender, and Pain SIG of the IASP. Studying sex and gender differences in pain and analgesia: a consensus report. Pain. 2007; 132 Suppl 1:S26-S45.

22. Ellermeier W, Westphal W. Gender differences in pain ratings and pupil reactions to painful pressure stimuli. Pain. 1995;61(3):435-439.

23. Kállai I, Barke A, Voss U. The effects of experimenter characteristics on pain reports in women and men. Pain. 2004;112(1-2):142-147.

24. Karos K, Niederstrasser N, Abidi L, Bernstein DP, Bader K. Factor structure, reliability, and known groups validity of the German version of the Childhood Trauma Questionnaire (Short-form) in Swiss patients and nonpatients. J Child Sex Abus. 2014;23(4):418-430.

25. Bernstein DP, Fink L, Handelsman L, et al. Initial reliability and validity of a new retrospective measure of child abuse and neglect. $\mathrm{Am}$ J Psychiatry. 1994;151(8):1132-1136.

26. Wingenfeld K, Spitzer C, Mensebach C, et al. [The German version of the Childhood Trauma Questionnaire (CTQ): preliminary psychometric properties]. Psychother Psychosom Med Psychol. 2010;60(11):442-450. German.

27. Klinitzke G, Romppel M, Häuser W, Brähler E, Glaesmer H. [The German Version of the Childhood Trauma Questionnaire (CTQ): psychometric characteristics in a representative sample of the general population]. Psychother Psychosom Med Psychol. 2012;62(2):47-51. German.

28. Kroenke K, Spitzer RL, Williams JB. The PHQ-9: validity of a brief depression severity measure. J Gen Intern Med. 2001;16(9):606-613.

29. American Psychiatric Association. (2013). Diagnostic and statistical manual of mental disorders (5th ed.). Arlington, VA: American Psychiatric Publishing.

30. Kroenke K, Spitzer RL, deGruy FV 3rd, Swindle R. A symptom checklist to screen for somatoform disorders in primary care. Psychosomatics. 1998;39(3):263-272.

31. Kroenke K, Spitzer RL, Williams JB. The PHQ-15: validity of a new measure for evaluating the severity of somatic symptoms. Psychosom Med. 2002;64(2):258-266.

32. Hanel G, Henningsen P, Herzog W, et al. Depression, anxiety, and somatoform disorders: vague or distinct categories in primary care? Results from a large cross-sectional study. J Psychosom Res. 2009;67(3): 189-197.

33. Sullivan MJL, Bishop SR, Pivik J. The Pain Catastrophizing Scale: development and validation. Psychol Assess. 1995;7(4):524-532.

34. Meyer K, Sprott H, Mannion AF. Cross-cultural adaptation, reliability, and validity of the German version of the Pain Catastrophizing Scale. J Psychosom Res. 2008;64(5):469-478.
35. Flaherty SA. Pain measurement tools for clinical practice and research. AANA J. 1996;64(2):133-140.

36. Gibson SJ, Farrell M. A review of age differences in the neurophysiology of nociception and the perceptual experience of pain. Clin J Pain. 2004;20(4):227-239.

37. Ferreira PH, Beckenkamp P, Maher CG, Hopper JL, Ferreira ML. Nature or nurture in low back pain? Results of a systematic review of studies based on twin samples. Eur J Pain. 2013;17(7):957-971.

38. Sherman JJ, LeResche L. Does experimental pain response vary across the menstrual cycle? A methodological review. Am J Physiol Regul Integr Comp Physiol. 2006;291(2):R245-R256.

39. de Tommaso M. Pain perception during menstrual cycle. Curr Pain Headache Rep. 2011;15(5):400-406.

40. Hayes AF. PROCESS: A Versatile Computational Tool for Observed Variable Mediation, Moderation, and Conditional Process Modeling [White Paper]. 2012. Available from: http://www.afhayes.com/public/ process2012.pdf. Accessed: January 20, 2015.

41. Eslick GD, Koloski NA, Talley NJ. Sexual, physical, verbal/emotional abuse and unexplained chest pain. Child Abuse Negl. 2011;35(8): 601-605.

42. Spertus IL, Yehuda R, Wong CM, Halligan S, Seremetis SV. Childhood emotional abuse and neglect as predictors of psychological and physical symptoms in women presenting to a primary care practice. Child Abuse Negl. 2003;27(11):1247-1258.

43. Kuo JR, Khoury JE, Metcalfe R, Fitzpatrick S, Goodwill A. An examination of the relationship between childhood emotional abuse and borderline personality disorder features: the role of difficulties with emotion regulation. Child Abuse Negl. 2015;39:147-155.

44. Mills P, Newman EF, Cossar J, Murray G. Emotional maltreatment and disordered eating in adolescents: testing the mediating role of emotion regulation. Child Abuse Negl. 2015;39:156-166.

45. Min MO, Minnes S, Kim H, Singer LT. Pathways linking childhood maltreatment and adult physical health. Child Abuse Negl. 2013;37(6): 361-373.

46. Alciati A. Different types of childhood adverse experiences and mood disorders. In: Juruena MF, editor. Clinical, Research and Treatment Approaches to Affective Disorders. Rijeka: InTech; 2012:143-164. Available from http://cdn.intechopen.com/pdfs-wm/30150.pdf. Accessed: January 26, 2015.

47. McCrory E, De Brito SA, Viding E. Research review: the neurobiology and genetics of maltreatment and adversity. J Child Psychol Psychiatry. 2010;51(10):1079-1095.

48. McCrory E, De Brito SA, Viding E. The link between child abuse and psychopathology: a review of neurobiological and genetic research. $J$ R Soc Med. 2012;105(4):151-156.

49. Davis DA, Luecken LJ, Zautra AJ. Are reports of childhood abuse related to the experience of chronic pain in adulthood? A meta-analytic review of the literature. Clin J Pain. 2005;21(5):398-405.

50. Kessler RC, McLaughlin KA, Green JG, et al. Childhood adversities and adult psychopathology in the WHO World Mental Health Surveys. Br J Psychiatry. 2010;197(5):378-385.

51. Bailer J, Witthöft M, Wagner H, Mier D, Diener C, Rist F. Childhood maltreatment is associated with depression but not with hypochondriasis in later life. J Psychosom Res. 2014;77(2):104-108.

52. Gibb BE, Butler AC, Beck JS. Childhood abuse, depression, and anxiety in adult psychiatric outpatients. Depress Anxiety. 2003;17(4):226-228.

53. van Dessel N, den Boeft M, van der Wouden JC, et al. Non-pharmacological interventions for somatoform disorders and medically unexplained physical symptoms (MUPS) in adults. Cochrane Database Syst Rev. 2014;11:CD011142.

54. Eccleston C. Role of psychology in pain management. Br J Anaesth. 2001; 87(1):144-152.

55. Kamper SJ, Apeldoorn AT, Chiarotto A, et al. Multidisciplinary biopsychosocial rehabilitation for chronic low back pain. Cochrane Database Syst Rev. 2014;9:CD000963. 


\section{Publish your work in this journal}

Neuropsychiatric Disease and Treatment is an international, peerreviewed journal of clinical therapeutics and pharmacology focusing on concise rapid reporting of clinical or pre-clinical studies on a range of neuropsychiatric and neurological disorders. This journal is indexed on PubMed Central, the 'PsycINFO' database and CAS,

and is the official journal of The International Neuropsychiatric Association (INA). The manuscript management system is completely online and includes a very quick and fair peer-review system, which is all easy to use. Visit http://www.dovepress.com/testimonials.php to read real quotes from published authors.

Submit your manuscript here: http://www.dovepress.com/neuropsychiatric-disease-and-treatment-journal 